\title{
A INVENÇÃO DE HUGO CABRET: ILUSTRAÇÃO E CINEMA NA LITERATURA JUVENIL
}

\author{
Maisa Barbosa da Silva Cordeiro* \\ Universidade Federal de Mato Grosso do Sul \\ Célia Regina Delácio Fernandes** \\ Universidade Federal da Grande Dourados
}

\begin{abstract}
Resumo: Este artigo analisa a obra A invenção de Hugo Cabret, de Brian Selznick (2007), ambientada na Paris de 1930. O objetivo deste estudo é verificar o diálogo verbo-visual na obra, catalogada como juvenil e integrante do acervo de 2013 do Programa Nacional Biblioteca da Escola - PNBE. O livro traz a ficção da história de Hugo Cabret, que perdeu o pai e precisa sobreviver sozinho, ao lado da história de George Méliès, importante cineasta das primeiras décadas do século XX. A narrativa evidencia a vida de Hugo Cabret, que, em meio às dificuldades particulares da adolescência, lida, ainda, com a ausência do pai, a morte de seu tio Claude, seu único parente, a fome, a solidão e a necessidade de construir sua identidade. Destacam-se, dessa forma, três questões: o diálogo verbo-visual; a representação do cinema; a representação da história de George Méliès. Nessa perspectiva, a análise pautase, principalmente, em Camargo (2003) e Groppo (2000).
\end{abstract}

Palavras-chave: Literatura juvenil. Verbo-visual. PNBE.

\section{Introdução}

\begin{abstract}
Mas antes de virar a página, quero que você se imagine sentado no escuro, como no início de um filme. Na tela, o sol logo vai nascer, e você será levado em zoom até uma estação de trem no meio da cidade. Atravessará correndo as portas de um saguão lotado. Vai avistar um menino no meio da multidão e ele começará a se mover pela estação. Siga-o, porque este é Hugo Cabret. Está cheio de segredos na
\end{abstract}

\section{Esta obra está licenciada sob uma Creative Commons - Atribuição 4.0}

\footnotetext{
* Doutoranda em Estudos Literários pela Universidade Federal de Mato Grosso do Sul - UFMS. Mestre em Literatura e Práticas Culturais pela Universidade Federal da Grande Dourados - UFGD (2013). Atualmente é professora no Centro Universitário da Grande Dourados - UNIGRAN. Tem experiência na área de Letras, com ênfase em políticas públicas de leitura, literatura infantil e juvenil e letramento literário. Membro do grupo de pesquisa Letramento em meios populares: Retratos de leitores - Fase 2, coordenado pela Profa. Dra. Ana Lucia Espindola. E-mail: <maysa_bdasilva@yahoo.com.br>.

** Doutora em Teoria e História Literária pela Universidade Estadual de Campinas - UNICAMP (2004). Mestre em Teoria Literária e Literatura Comparada pela Universidade Estadual Paulista Júlio de Mesquita Filho UNESP (1996). Atualmente é professora associada, pesquisadora e extensionista da Faculdade de Comunicação, Artes e Letras da Universidade Federal da Grande Dourados - UFGD. Tem experiência na área de Letras, com ênfase em Literatura e Ensino, atuando principalmente nos seguintes temas: história da leitura, formação de leitores, letramento literário, literatura infantojuvenil e políticas públicas de leitura. Líder do grupo de pesquisa CEELLE - Centro de Estudos em Ensino, Leitura, Literatura e Escrita - UFGD. E-mail: $<$ celiafernandes@ufgd.edu.br>.
} 
cabeça, esperando que sua história comece (SELZNICK, 2007, s/p).

A invenção de Hugo Cabret, do norte-americano Brian Selznick, publicada no ano de 2007 e traduzida para o português por Marcos Bagno, conta a história de um adolescente na Paris de 1930. Hugo cresceu na Estação Central de Paris, furtando pequenos objetos de lojas para reconstruir um autômato (homem mecânico) deixado por seu pai. Em um de seus furtos, é pego por um dono de uma loja de brinquedos que ameaça queimar o caderno que carrega herança de seu pai - e que o obriga a trabalhar para pagar os furtos. Assim, Hugo conhece Isabelle, que o fará vivenciar inúmeras aventuras em busca do passado e do autoconhecimento. O livro põe em cena a busca de Hugo por sua identidade, a necessidade de conhecer seu passado e a construção de sua personalidade em meio às dificuldades pelas quais passou. Nesse cenário, evidencia-se, nesse percurso, a necessidade de Hugo de melhorar a si próprio enquanto sujeito.

A obra apresenta peculiar trabalho com os textos verbal e visual. Direcionada ao público juvenil, nota-se que se, na maioria das obras para jovens, as palavras prevalecem sobre as ilustrações, em $A$ invenção de Hugo Cabret, várias páginas são destinadas às imagens. Com isso, se, em algumas páginas, a narrativa é feita pelo texto escrito, na sequência, o imagético dá continuidade à história, tornando os o verbal o visual indissociáveis para a construção de sentidos. O trabalho artístico é bastante presente no livro, que integra diferentes códigos, fulcrais à leitura.

É relevante o fato de se tratar de uma tradução, tendo em vista que as obras estrangeiras são cada vez mais presentes nas prateleiras de bibliotecas e livrarias brasileiras. Encontrar, portanto, entre os inúmeros títulos Best-sellers produções que dialoguem de modo crítico com o jovem e que busquem integrá-lo ao mundo artístico se faz extremamente necessário. Entre a gama de títulos que alcançam altas vendagens, a maior parte constitui-se de traduções, evidenciando a necessidade de se refletir acerca da qualidade literária de tais produções.

Com efeito, Santos (2010, p. 25), em levantamento das teses com foco na tradução na literatura infantojuvenil relata o pouco número de pesquisas acerca das traduções destinadas ao público infantojuvenil: “[...] foram encontrados onze trabalhos cobrindo a intersecção entre Estudos da Tradução e Literatura Infanto-Juvenil. Esses trabalhos dividemse em oito dissertações de mestrado e três teses de doutorado". Além disso, em levantamento feito no Banco de Teses da Capes é possível verificar, também, a ausência de estudos específicos acerca da tradução da literatura juvenil. Estudar, portanto, a construção literária 
em uma obra traduzida parece, portanto, primordial em vista do escasso número de pesquisas com este foco.

A obra foi selecionada para compor o acervo de 2013 do Programa Nacional Biblioteca da Escola (PNBE), programa federal lançado em 1997 com o objetivo de "[...] diminuir a barreira entre o aluno e o livro" (BRASIL, 2011). Anualmente, o PNBE envia acervos literários às escolas públicas de todo o Brasil, favorecendo a criação e ampliação das bibliotecas escolares, com obras selecionadas por meio de parcerias com professores atuantes em universidades federais brasileiras. Desde sua gênese, é o principal programa de fomento à leitura. Dessa maneira, ao ser selecionada por um programa de âmbito nacional, a obra poderá encontrar leitores de diversas escolas públicas brasileiras, o que justifica o seu estudo.

\section{Literatura juvenil: breve histórico}

A partir do século XVIII, na Europa, verificou-se que, devido à consolidação das instituições burguesas como família e escola, a infância passou a ser vista de forma diferenciada e a criança deixou de ser tratada como um adulto em miniatura. Com isso, os valores surgidos com o advento da família burguesa passaram a ser transmitidos à criança de modo diferenciado do adulto: "Se antes a criança acompanhava a vida social daquele, estava imersa naquele mundo, agora ela deveria dele se retirar, só podendo nele entrar depois de receber o preparo de uma educação adequada" (FERNANDES, 2007, p. 2).

Nesse processo, o jovem também passou pela vigilância, conforme aponta Groppo (2000, p. 57): “[...] A criança e, em seguida, o jovem são submetidos a esta instituição que os isola do convívio promíscuo com os adultos, marca neles uma condição diferenciada [...] e uma condição inferior". Desse modo, aos poucos, a compreensão de crianças e jovens enquanto sujeitos distintos dos adultos contribui para mudanças no modo de educá-los.

Historicamente, foram sendo construídas novas concepções no que diz respeito à infância e à juventude: “[...] Através da modernidade, a infância e a juventude foram consideradas estágios perigosos e frágeis da vida dos indivíduos. Crianças e, por extensão, jovens foram vistos como propícios a construírem toda espécie de males” Groppo (2000, p. 59).

Isso influenciou significativamente o modo com que as obras literárias eram produzidas, pois a literatura destinada a esse público era permeada de ideais e valores que os adultos buscavam incutir nos pequenos leitores. Também a forte ligação da literatura com a instituição escolar impactou a produção das obras. Para Souza (2001, p. 29): “[...] a produção para jovens, nas suas origens, esteve muito ligada ao desenvolvimento da educação escolar, 
surgindo da necessidade de se usarem livros para atender aos objetivos de universalização do ensino". O elo entre literatura e escola, no entanto, não se restringiu apenas a determinada época, sendo perceptível até hoje:

A partir de meados de 1970, a produção infanto-juvenil responde por uma significativa parcela do mercado editorial brasileiro. E a escola, mais do que nunca, representa o local onde se captam as expectativas para a criação de uma literatura adequada para crianças e jovens e para onde convergem as atenções dos interessados na divulgação e manutenção dos seus próprios valores, numa espécie de círculo vicioso (SOUZA, 2001, p. 32).

Nesse contexto, as obras traduzidas são um investimento constante por parte do mercado editorial que, muitas vezes, consegue que algumas obras sejam divulgadas em diversos países, sendo fundamental o estudo dessas obras visto que, muitas delas, passam a integrar as prateleiras escolares, seja por compras da própria escola ou por intermédio de políticas públicas, como o PNBE.

Em terras brasileiras, é no fim do século XIX que começam a chegar obras destinadas ao público infantojuvenil, com as adaptações de Figueiredo Pimentel e Carlos Jansen dos contos de fadas europeus. Assim, era perceptível a dependência às obras europeias, enquanto que o repertório de contos da tradição oral no Brasil não era considerado. Apenas no início do século XIX os referentes nacionais passam a ser inseridos nas obras, por autores Olavo Bilac, Coelho Neto e Manuel Bonfim.

É somente com Lobato, por volta de 1920, que a literatura infantojuvenil destinou-se especificamente às crianças brasileiras, utilizando-se de temas relacionados ao mundo infantil, de uma linguagem cotidiana e tendo-as como protagonistas.

Contudo, foi somente a partir dos anos de 1970 que a literatura infantojuvenil começou a ser produzida de forma maciça, devido à ampliação das escolas, fator decisivo tanto no aumento no número de obras produzidas quanto na preocupação com a sua qualidade. Com o grande número de pesquisas na área, motivadas pelas dificuldades dos próprios professores em atrair leitores, começou-se, cada vez mais, a afastar a literatura infantojuvenil de um objetivo pedagogizante e inseri-la no círculo cultural dos alunos. Para Magnani (2001, p. 87), foi a época em que houve a "democratização do ensino", devido ao crescimento do público urbano e de classe média. Esse aumento contribuiu para a ampliação do consumo de livros. Com isso, a produção literária infantojuvenil passou a focar exatamente no que a escola precisava para auxiliar no processo de ensino/aprendizagem, motivada pela busca por vendagem, por parte do setor livreiro e pela necessidade de apregoar valores formativos de um governo ditatorial: 
[...] Amparados pela legislação educacional e/ou pelo paternalismo do Estado, editores e autores começam a empregar de forma mais racional o caráter utilitarista da escola conjugado ao agradável dos recursos da mídia, para satisfazer às velhas necessidades de fantasia e ficção, agora as dos segmentos populares que têm (?) acesso à escolarização (MAGNANI, 2001, p. 87).

Com a ampliação das produções literárias destinadas aos pequenos e jovens leitores começaram a surgir novos questionamentos acerca da especificidade tanto para a criança quanto para o jovem e, antes uma distinção aparentemente pacífica: literatura infantojuvenil/adulta cede lugar à outra distinção bastante conflituosa: literatura infantil/juvenil.

No entanto, se os estudos da academia não dão tanta atenção à literatura para o jovem, não são poucos os investimentos editoriais para esse público. Isso quer dizer que, a partir do pouco número de pesquisas na área e no grande número de lançamentos literários, é necessário pensar sobre o lugar da literatura juvenil no sistema literário.

É preciso refletir sobre o porquê de conflitos relacionados à temática, projeto gráfico e ilustrações fazerem com que escritores cujas obras circulam sob o rótulo de 'juvenil' costumam negar que escrevem especificamente para esse público. A questão é que, no que tange a temática, certas obras podem ser destinadas tanto ao público juvenil quanto ao público adulto. No que diz respeito a projeto gráfico e ilustração, porém, percebem-se as marcas do endereçamento ao público juvenil, permitindo a conclusão de que a literatura juvenil está em uma zona de fronteira entre o infantil e o adulto, mas que os conflitos relacionados ocorrem, principalmente, por ele estar também entre as exigências de mercado editorial e as de qualidade literária.

A delimitação da literatura juvenil torna-se complicada inicialmente porque a própria delimitação do termo juventude não é algo fácil. Não é possível delimitar, segundo Groppo (2000), uma faixa etária precisa para a juventude. Irá depender dos valores culturais de cada região, cada cultura, cada organização social. Para Groppo (2000, p. 8):

\footnotetext{
Ao ser definida como categoria social, a juventude torna-se, ao mesmo tempo, uma representação sociocultural e uma situação social [...]. Ou seja, a juventude é uma concepção, representação ou criação simbólica, fabricada pelos grupos sociais ou pelos próprios indivíduos tidos como jovens, para significar uma série de comportamentos e atitudes a ele atribuídos. Ao mesmo tempo, é uma situação vivida em comum por certos indivíduos.
}

Assim, a delimitação do que é ser jovem é particular, baseada em valores sociais e individuais. Os grupos e instituições sociais fazem tais definições de acordo com interesses, concepções e valores específicos, anulando qualquer possibilidade de se definir de modo estanque o período em que se é ou não jovem. Nesse contexto, como destaca Gregorin Filho 
(2001, p. 41),

\begin{abstract}
A literatura feita para o jovem da atualidade está vinculada à arte, isto é, ao mesmo tempo em que traz à tona as discussões de valores sociais, devolve para a sociedade novas maneiras artísticas de discutir e veicular esses valores, seja por meio de múltiplas linguagens, seja por intermédio das atuais formas de suporte para que essa arte seja veiculada.
\end{abstract}

É devido a essas questões, portanto, que ocorrem dificuldades para delimitar obras ou autores como sendo destinados aos jovens, pois muitas "parecem situar-se em uma zona fronteiriça, um pouco obscura e mal explorada, entre a literatura para adultos e a literatura para crianças" (BECKETT, 1997, p. 249 apud CRUVINEL, 2009, p. 17). Em busca da legitimação da existência de uma literatura juvenil, apesar de pouco estudada, é possível encontrar polêmicas em relação a essa classificação. Enquanto que, para uns, é necessário haver produção para esse público, com o objetivo da literatura juvenil deixar de ser considerada 'menor', para outros, é necessário que deixe de haver a existência de 'rótulos', não havendo, portanto, necessidade de se direcionar o livro a um público específico.

Uma questão muito recorrente é a tradução de obras juvenis para este público, o que torna fundamental o estudo dessas obras, por ser um forte meio de lucratividade das editoras. Em pesquisa acerca das traduções infantojuvenis no Brasil, Verdolini $(2012$, p. 1) aponta que: "A tradução existe como uma das possibilidades de compreender o mundo circundante, o universo cultural e as diferentes políticas”. Com efeito, ao emigrar para outro país, a obra leva representações de culturas, valores, modos de organização social etc. A autora destaca, contudo, a carência de estudos, tanto em pesquisas de pós-graduação quanto em obras que abordem a história da literatura juvenil, sobre a tradução para este público.

Sabe-se, porém, que a literatura juvenil representa um importante filão no mercado editorial e, com isso, estudos a respeito das obras para o público juvenil estão se ampliando. Um dos elementos a serem estudados nestas obras é, sem dúvida, o projeto gráfico e, por intermédio, as ilustrações. Nas produções para crianças, já possuem seu lugar cativo, sendo verdadeiros trabalhos artísticos. Nas obras destinadas aos leitores jovens, no entanto, é distinto o trabalho com as ilustrações.

Para os pequenos, ainda iniciantes no campo da leitura, as ilustrações estimulam, de acordo com Cademartori $(2008$, p. 86), um prazer de ordem sensorial que "provém do envolvimento com as cores, formas e texturas". Já em relação aos jovens, as ilustrações são mais complexas e, muitas vezes, dialogam com outras obras, possibilitando a intervenção do leitor "na construção de sentidos e na formulação de hipóteses para a interpretação do narrado" (CADEMARTORI, 2008, p. 87), por meio do repertório de leitura de cada um. 
Nota-se que a ilustração não deixa de ter sua importância nas publicações para os jovens, apenas são produzidas com outros objetivos: mais complexas, contribuem para o aprimoramento do gosto estético entre os leitores. Para Werneck (1986, p. 156), a ilustração, quando trabalhada adequadamente dentro da obra, "aguça a percepção, desenvolve a observação e forma no jovem leitor uma espécie de proteção contra o bombardeio diário de materiais visuais estereotipados".

Após discutir aspectos relacionados à relevância da literatura juvenil contemporaneamente, passa-se ao estudo da obra A invenção de Hugo Cabret. Para proceder à análise, utilizam-se, também, as funções da imagem propostas por Camargo:

\begin{abstract}
O pesquisador e ilustrador Luis Camargo, em seu livro Ilustração no livro infantil (1995), atribui diferentes funções à imagem no livro literário, baseando-se nas funções da linguagem propostas por Jakobson. Em texto posterior, Camargo (2003) revê o estudo e atribui novas funções à imagem. Dessa forma, de acordo com Camargo (2003), a imagem pode ser representativa, ao imitar um objeto; descritiva, ao descrever objetos ou cenários; narrativa, quando a sequência das imagens conta a história; simbólica, ao orientar para um significado metafórico; expressiva, quando voltada para os sentimentos ou valores dos personagens; estética, quando atenta para o aspecto visual ou para figuras de linguagem; lúdica, quando chama a atenção para o jogo; conativa, ao buscar influenciar o receptor, como em propagandas; metalinguística, quando se volta para a linguagem; fática, quando orientada para o suporte material que compõe a imagem e, finalmente, a pontuação, cujo papel é representado por vinhetas e pela capitular (FERNANDES; CORDEIRO, 2011, p. 18-19).
\end{abstract}

Assim, ao verificar as funções da ilustração no livro literário com base em Camargo (2003), deve-se levar em conta que, muitas vezes, podem ser encontradas mais de uma função em determinada imagem e, com isso, irão ser apontadas as funções da imagem em ilustrações do livro.

\title{
A construção da identidade do jovem em $A$ invenção de Hugo Cabret
}

Hugo Cabret é um menino órfão que vive escondido na central de trem de Paris dos anos 1930. Esgueirando-se por passagens secretas, Hugo cuida dos gigantescos relógios do lugar: escuta seus compassos, observa os enormes ponteiros e responsabiliza-se pelo funcionamento das máquinas. A sobrevivência de Hugo depende do anonimato - ele tenta se manter invisível porque guarda um incrível segredo, que é posto em risco quando o severo dono da loja de brinquedos da estação e sua afilhada cruzam o caminho do garoto. Um desenho enigmático, um caderno valioso, uma chave roubada e um homem mecânico estão no centro desta intrincada e imprevisível história, que, narrada por texto e imagens, mistura elementos dos quadrinhos e do cinema, oferecendo uma diferente e emocionante experiência de leitura (SELZNICK, 2007). 
A citação acima, mais do que apresentar o protagonista Hugo Cabret, instiga o leitor a viver a história do jovem. De modo convidativo, deixa clara a existência de enigmas, segredos e mistérios que serão desvendados ao longo da narrativa. O livro aqui analisado possui, todo tempo, o tom do mistério que tanto atrai os leitores, independentemente da idade. Hugo Cabret, mais do que protagonista da obra, mostra ao jovem leitor a necessidade de ser protagonista da vida, das decisões, da busca pela autonomia. Entre dores e alegrias, a narrativa de sua trajetória descortina para o leitor imensas possibilidades de caminhos e escolhas.

As ilustrações do livro são todas em preto e branco, excedendo-se a capa e a contracapa, com a técnica lápis em papel Fabriano Artístico. As sequências de ilustrações guardam semelhança com o cinema: há sempre uma continuidade que permite o leitor acompanhar a narrativa por meio delas. Há, ainda, reproduções de filmes variados, como o filme Viagem à lua, de 1902; A Clock Store [A relojoaria], 1931, desenho animado de Walt Disney; Le Million [O milhão], 1931, René Clair, entre outros.

A história se inicia com pequenos roubos cometidos por Hugo, alguns para poder comer e, em outros momentos, ele furtava objetos de uma loja de brinquedos: "Hoje o velho parecia agitado. Será que descobriu que alguns de seus brinquedos sumiram? Bem, já não era possível fazer nada sobre isso agora. Hugo precisava dos brinquedos" (SELZNICK, 2007, p. 47).

Figura 1: Hugo Cabret e a loja de brinquedos

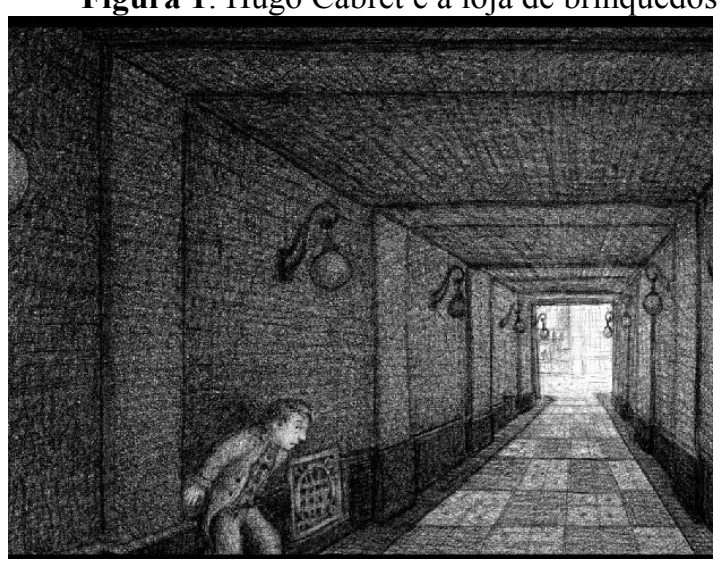

Fonte: A invenção de Hugo Cabret (2007).

Figura 3: O dono da loja

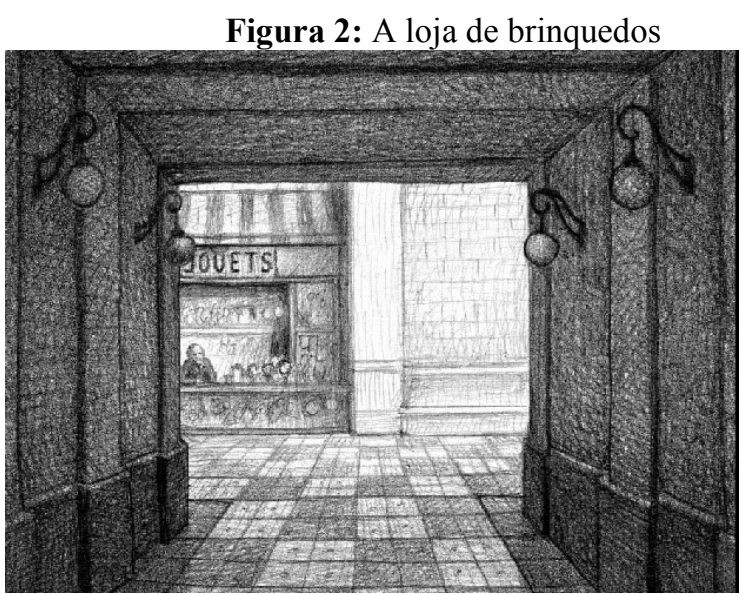

Fonte: A invenção de Hugo Cabret (2007).

Figura 4: $\mathrm{O}$ dono da loja desconfia de Hugo 




Fonte: A invenção de Hugo Cabret (2007).

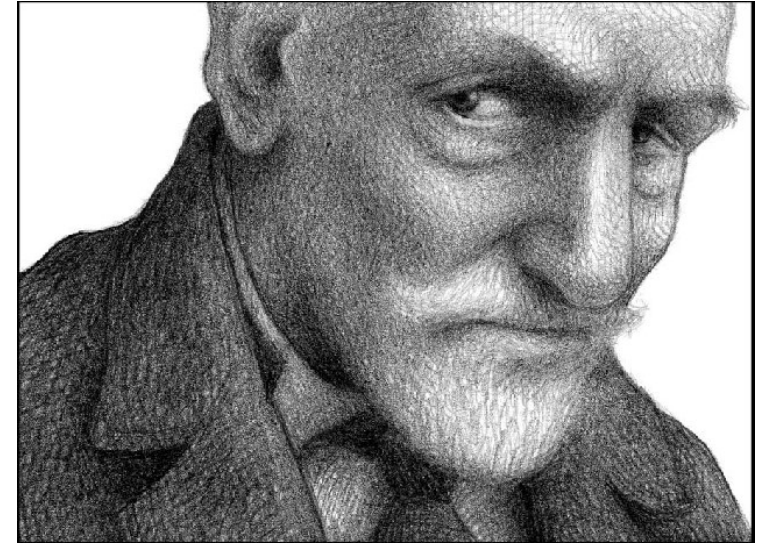

Fonte: A invenção de Hugo Cabret (2007).

Nota-se, claramente, a função narrativa (CAMARGO, 2003), pois a primeira ilustração mostra Hugo enquanto se prepara para um de seus furtos e o modo com que observa o dono da loja de brinquedos. Este, na quarta ilustração, aparece desconfiado dos movimentos do menino. Dessa forma, os acontecimentos vão se modificando a cada ilustração. Mas, também, as imagens deixam clara a caracterização do ambiente e do personagem que, mais tarde, é revelado como George Méliès, sendo possível atribuir também as funções representativa e descritiva propostas por Camargo (2003). O livro divide imagens de autoria de Selznick e imagens retiradas de filmes do início do século XX, dos filmes de Méliès e de outros cineastas, conduzindo o leitor a uma retomada na história do cinema.

Os planos de Hugo se complicam no momento em que o dono da livraria descobre seus furtos e, além disso, toma o caderno de anotações do qual ele nunca se separa:

Hugo rosnou feito um cachorro. Estava furioso consigo mesmo por ter sido apanhado [...]. O menino se debateu contra o velho, mas em vão. Por fim, Hugo enfiou a mão trêmula no bolso e de lá tirou seu caderninho de papelão surrado. A capa estava lisa de tão esfregada. Sem relaxar o aperto no braço do menino, o velho agarrou o caderninho, levou-o para longe do alcance de Hugo, abriu e folheou. Uma página chamou sua atenção (SELZNICK, 2007, p. 51).

O caderno de Hugo contém desenhos feitos pelo seu pai, um relojoeiro que descobre um autômato abandonado em um museu:

\footnotetext{
- 'Capitão! - ele dissera a Hugo, que já estava na cama. - desculpe ter demorado tanto, mas encontrei uma coisa fascinante no museu esta noite... no sótão. Parece que ninguém sabe como foi parar ali. Nem mesmo o velho guarda, mas de todo modo ele não se lembra de quase nada. É a máquina mais bonita e complexa que já vi. É uma pena que o museu não tenha cuidado dela' (SELZNICK, 2007, p. 114).
}

Mais do que ser o único meio de Hugo reconstruir o autômato, o caderno guarda a importância de ser o único vínculo direto que tem com o pai: por meio dele, consegue encontrar semelhanças entre eles, por meio do mesmo gosto por máquinas e por descobertas: 
Figura 5: A reconstrução do autômato

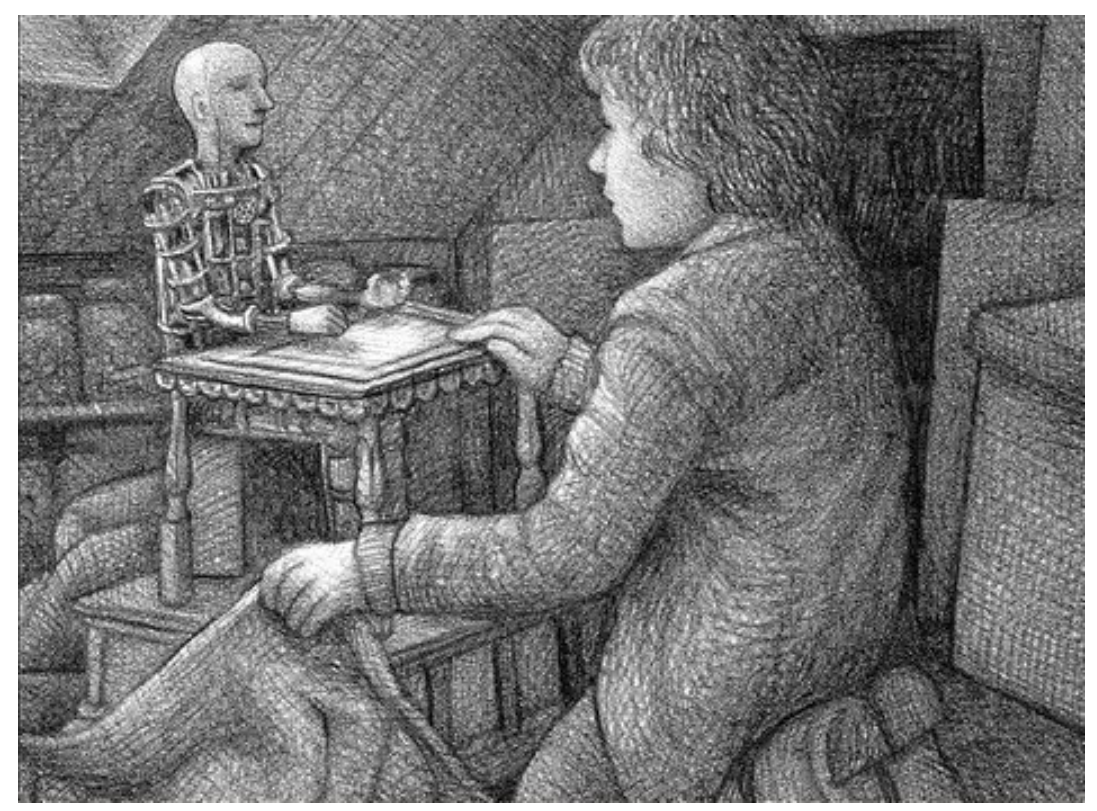

Fonte: A invenção de Hugo Cabret (2007).

Na imagem, fica perceptível a função descritiva (CAMARGO, 2003), pois é possível visualizar o autômato detalhadamente, bem como o olhar de fascínio de Hugo pelo objeto.

Quando encontra o autômato, o pai de Hugo busca consertá-lo, o que faz com que ele permaneça longas noites no trabalho até que, em uma noite, na qual o pai estava demorando mais do que de costume, a porta se abre já pela manhã, mas quem aparece é o tio de Hugo, Claude:

- Junte logo todas as suas coisas, sobrinho - disse tio Claude, com um bafo de álcool, como sempre. Tirou seus pequenos óculos de metal com uma das mãos e enxugou os olhos avermelhados com a outra. - Seu pai morreu e, como seu único parente vivo sou eu, vou cuidar de você (SELZNICK, 2007, p. 124).

Hugo, portanto, aprende a lidar com a morte do pai ao mesmo tempo em que precisa começar a roubar comida, por ordem do tio. Do mesmo modo, também tem que abandonar a escola e aprender a manter os relógios da estação, emprego do tio, que passa a tarefa ao menino. O tio, alcoólatra, passa longos dias longe de casa e Hugo assume de vez a responsabilidade de manter os relógios da estação, até que, passado algum tempo, o tio simplesmente não retorna.

Durante o tempo em que esteve com o tio, Hugo encontra novamente o autômato, nos destroços do incêndio no qual o pai morreu e Hugo passa a se dedicar totalmente a consertá-lo, já que é o único elo entre ele e o pai. Portanto, para não ser mandado para o orfanato depois do sumiço do tio, Hugo precisa manter os relógios da estação em perfeito funcionamento, para que o inspetor, chefe do tio de Hugo, não desconfie de nada. 
O fato de Hugo ser tão ligado ao autômato, a ponto de dedicar sua vida a ele, é porque o autômato tem a capacidade de escrever. Os autômatos da época eram bem mais simples do que o que ele possuía e ele acreditava que, durante o tempo que o pai ficou consertando, havia deixado uma mensagem para ele:

Toda vez que pensava na mensagem, imaginava-a com a letra de seu pai. Podia ser que, enquanto trabalhava no autômato, no sótão do museu, seu pai tivesse mudado as pecinhas mecânicas o bastante para que escrevessem uma nova mensagem, uma mensagem destinada apenas a Hugo. Era possível, afinal de contas (SELZNICK, 2007, p. 133).

É no intuito de retomar o caderno que Hugo começa a trabalhar para o dono da loja e faz amizade com sua sobrinha: "Agora só precisava recuperar o caderno que estava com o velho para poder terminar seu trabalho e ler a mensagem deixada pelo pai" (SELZNICK, 2007, p. 133). Nesse momento, descobre-se o conteúdo do caderno de Hugo, que contém desenhos do autômato, feitos pelo seu pai.

Um dos meios de Hugo manter a ligação com o pai, além do autômato, está no gosto pelo cinema: ambos são aficionados por filmes e buscam assisti-los sempre que possível. Constata-se que não somente a vida de Hugo é marcada por aventuras, como também suas preferências em relação ao cinema e, também, as literárias, pois é leitor de Júlio Verne. Tais retomadas literárias e cinematográficas constituem importantes intertextos, contribuindo para a ampliação do arcabouço artístico do leitor. Ao se aproximar de Isabelle, sobrinha do dono da loja de brinquedos, consegue levá-la ao cinema, momento em que a representação do cinema se torna mais latente, pois Hugo começa a falar sobre seus filmes preferidos:

[...] As cortinas se fecharam, todo mundo aplaudiu, e o projecionista trocou os rolos. Passados uns instantes, as cortinas se abriram de novo e teve início a atração principal, $\mathrm{O}$ milhão, de um diretor chamado René Clair. Era sobre um artista, um bilhete de loteria perdido, um criminoso, um casaco emprestado e um cantor de ópera, e tinha uma das sequências de perseguição mais incríveis que Hugo já tinha visto. Achou que toda boa história devia terminar com uma grande e animada perseguição (SELZNICK, 2007, p. 203).

São inseridas, também, diversas imagens retiradas de filmes do início do século XX, do próprio Méliès, como Viagem à lua, além de filmes da década de 1930. Notam-se, na imagem, as funções descritiva e metalinguística (CAMARGO, 2003), pois busca atentar para o suporte inicial da imagem, o cinematográfico:

Figura 6: Imagem de Viagem à lua. 


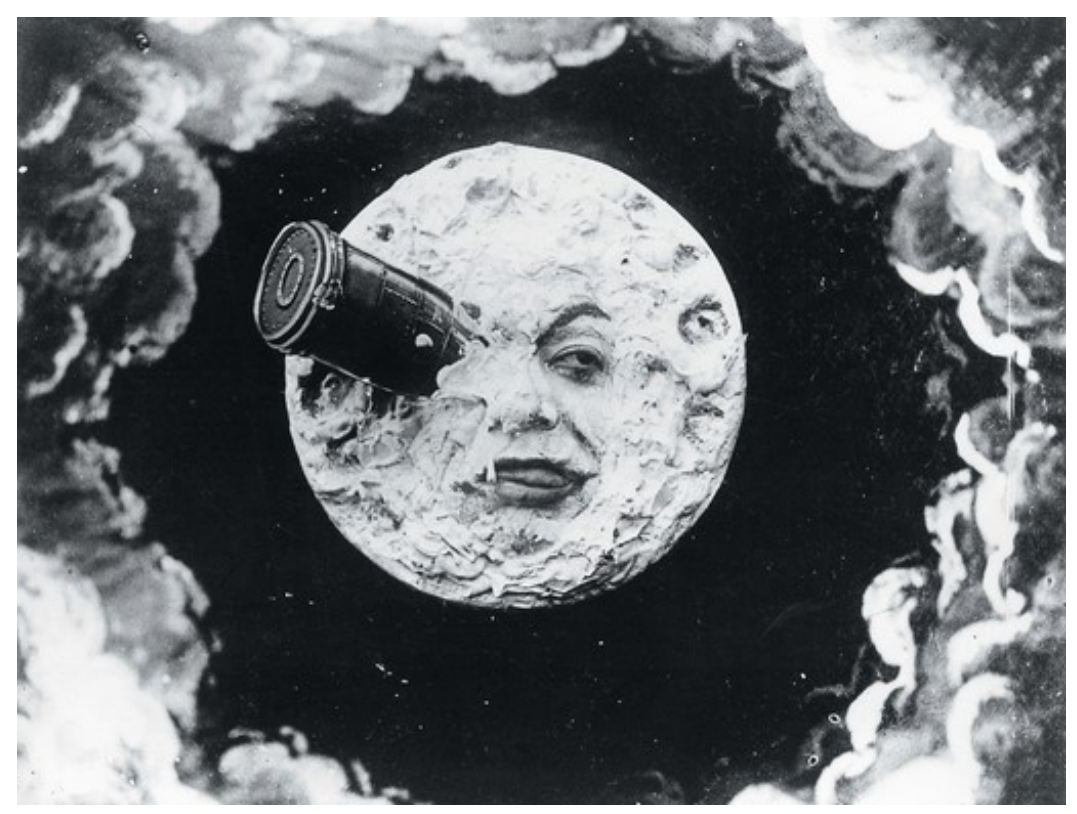

Fonte: A invenção de Hugo Cabret (2007).

Hugo e Isabelle, quando concluem o conserto do autômato, encontram a assinatura de George Méliès. Isabelle se surpreende com o fato de o autômato assinar o nome de seu tio e o confronta, trazendo a verdadeira história de seu tio, um famoso cineasta. O motivo de Méliès ter buscado o anonimato foi a morte dos pais de Isabelle, que morreram trabalhando em um de seus filmes. Essa história, literária, cruza-se com a verdadeira biografia de Mèliés, pois os jovens vão à busca de mais informações sobre ele e as encontram em uma biblioteca:

\begin{abstract}
O cineasta George Méliès começou sua carreira como mágico e possuía um teatro de mágicas em Paris. Essa ligação com a magia o ajudou a perceber imediatamente o potencial do novo suporte que era o cinema. Foi um dos primeiros a demonstrar que os filmes não tinham que refletir a vida real. Logo se deu conta de que o cinema tinha o poder de capturar sonhos. Méliès é amplamente reconhecido como o aperfeiçoador do truque da substituição, que tornava possível fazer as coisas aparecer e desaparecer na tela, como por magia. Isso mudou apara sempre a cara do cinema (SELZNICK, 2007, p. 354-355).
\end{abstract}

Méliès trouxe inúmeras contribuições à reinvenção do cinema, por aprofundar a ficcionalidade em seus filmes. Boa parte das obras do cineasta é inspirada em Júlio Verne e, também Hugo é um grande leitor deste escritor. Com isso, as histórias reais e literárias vão se entrecruzando ao longo do livro: Hugo Cabret, em seu tempo livre, assiste filmes de Méliés, com quem convive na narrativa, e se interessa por ficção assim como o cineasta. As relações metalinguísticas presentes na obra, portanto, vão se tornando cada vez mais próximas, permitindo o leitor circular entre literariedade e realidade ao longo da narrativa.

Hugo Cabret é um personagem em conflito. Com doze anos, precisou amadurecer cedo demais, já que perdeu o pai e se sustenta sozinho, por meio dos furtos. Porém, do mesmo 
modo, há momentos em que sua infância é percebida, como a amizade com Isabelle, que, por vezes, faz com que se esqueça dos problemas; e as brincadeiras com um livro de mágica, que também o transfere para o mundo da fantasia. A narrativa, portanto, aborda a trajetória de um jovem que amadurece cedo demais, devido às urgências impostas por sua trajetória, mas que, nem por isso, tem menos necessidade de se transpor para um mundo ficcional.

Com efeito, quando o mistério é solucionado e Hugo descobre o verdadeiro dono do autômato, a fantasia que o cerca não diminui, pelo contrário, o impele para construir seu próprio autômato, mais complexo que o anterior, capaz de escrever diversas páginas e fazer diversas ilustrações. Na verdade, ao chegar ao final da história, a imaginação chega ao ápice, quando o personagem Hugo diz:

Quando a gente dá corda, ele pode fazer algo que, tenho certeza, nenhum outro autômato no mundo faz. Ele pode contar a incrível história de George Méliès, sua esposa, sua afilhada e de um amado relojoeiro cujo filho cresceu e se tornou um mágico.

O complicado mecanismo do meu autômato pode produzir cento e cinquenta e oito ilustrações diferentes e pode escrever, letra por letra, um livro inteiro, vinte e seis mil cento e cinquenta e nove palavras. Estas palavras (SELZNICK, 2007, p. 510511).

Assim, o autômato de Hugo é colocado como o verdadeiro autor da obra, transportando o leitor, mais uma vez, para o plano da fantasia, evidenciando o elemento metalinguístico presente na narrativa.

São perceptíveis as contribuições das imagens para a constituição da obra aqui analisada e, constata-se o quanto o livro juvenil pode ser enriquecido com seu uso. No entanto, deve-se estar claro que não é somente a ilustração que cumpre o papel de acrescentar possibilidades de construção de sentidos no livro. Para Azevedo (1998, p. 107):

[...] um desenho simples, feito com poucos traços, sem maiores pretensões técnicas pode ser, sempre a meu ver, infinitamente melhor ilustração do que um desenho rebuscado, construído a partir de uma técnica requintadíssima, mas que em relação ao texto só consegue ser redundante (AZEVEDO, 1998, p. 107).

Nesse sentido, compreende-se que o diálogo entre os elementos do texto (texto verbal, texto não verbal e projeto gráfico) é mais importante do que o aspecto estético da ilustração. As ilustrações, na obra aqui analisada, vão além de reprodutoras do texto escrito: elas descortinam para o jovem leitor momentos da história do cinema, bem como o estimulam a ler, em alguns trechos, utilizando, prioritariamente, das ilustrações. Em A invenção de Hugo Cabret, caso o leitor não atente para as ilustrações, fará uma leitura parcial da narrativa.

De acordo com Sipe (2010, p. 96), mesmo que as ilustrações sejam recorrentes em 
obras para o público infantil, “[...] qualquer livro-ilustrado pode ser estudado por alunos de qualquer idade nos modos em que as ilustrações e palavras se relacionam, nas mídias artísticas usadas nas ilustrações, e nas possibilidades de significados e de interpretações das ilustrações”. Esse fato fica perceptível em A invenção de Hugo Cabret, cujas imagens, além de fundamentais para a construção de sentidos, são extremamente bem trabalhadas.

Sabe-se que, muito mais do que ser atrativa, a ilustração precisa dialogar com o texto verbal e com o projeto gráfico da obra. Assim, uma ilustração adequada para determinado livro não precisa ser, necessariamente, derivada de uma rebuscada técnica de pintura, o mais importante é que esteja em sintonia com os outros elementos do texto: “[...] um livro ilustrado, no nível da linguagem é composto de, pelo menos três sistemas narrativos que se entrelaçam: a) o texto propriamente dito [...] b) as ilustrações; c) o projeto gráfico" (AZEVEDO, 1998, p. 107). Por meio das funções das imagens propostas por Camargo (2003), pôde-se observar que as ilustrações podem ocupar diferentes funções dentro do livro, sendo mais do que meros chamarizes.

A invenção de Hugo Cabret, presente em diversas escolas públicas brasileiras por intermédio do PNBE, destaca-se por ofertar ao jovem leitor uma obra rica devido ao seu trabalho estético com as diversas manifestações artísticas - visuais, literárias e cinematográficas. É, portanto, uma importante opção aos mediadores de leitura, que, muitas vezes, encontram em um sem fim de opções de títulos, temas, cores, extensões, páginas, entre diversas outras questões a serem observadas no momento de se trabalhar com um livro em sala de aula. É relevante, ainda, pelas temáticas abordadas: Hugo sofre com a morte dos pais, com o abandono e morte de seu único tio, com a necessidade de roubar mesmo contra seus valores éticos. Em meio a tudo isso, como muitos jovens, Hugo precisa crescer e se constituir enquanto sujeito. Sem dúvida, a história desse jovem encontra a de muitos, que, assim como ele, vivenciam uma série de problemáticas sociais e familiares e, em meio a isso, enfrentam a necessidade de se impulsionar para o mundo adulto.

\section{Considerações finais}

Ao finalizar o estudo da obra, que traz, em seu bojo, a fantasia associada à realidade; o conhecimento sobre a história do cinema; os conflitos típicos dos adolescentes ao lado dos problemas advindos da perda do pai e da dificuldade financeira, além de diversos outros aspectos, é possível defender que ela favorece o tipo de descoberta que propõe Abramovich (1995, p. 17): 
É através duma história que se podem descobrir outros lugares, outros tempos, outros jeitos de agir e de ser, outra ética, outra ótica... É ficar sabendo História, Geografia, Filosofia, Política, Sociologia, sem precisar saber o nome disso tudo e muito menos achar que tem cara de aula... Porque, se tiver, deixa de ser literatura, deixa de ser prazer e passa a ser Didática, que é outro departamento (não tão preocupado em abrir as portas da compreensão do mundo).

Com isso, busca-se ressaltar, neste trabalho, que as obras destinadas aos jovens que, constantemente apresentam “[...] unos temas que, tanto desde la óptica editorial como desde la intención asumida voluntariamente por algunos creadores, se consideran como reflejos de las preocupaciones o intereses de los jóvenes actuales" (PADRINO, 2005, p. 63), além do projeto gráfico voltado para atrair o jovem leitor, precisa estar, cada vez mais, sob o olhar da academia, visto que consistem em uma etapa fundamental na formação do leitor literário, bem como na formação humana.

Nesse sentido, A invenção de Hugo Cabret destaca-se entre a gama de obras destinadas ao jovem. Ao contrário da maioria dessas produções, que pouco acrescenta ao seu espírito crítico, inventivo e estético, o livro aqui discutido apresenta um jovem com medos, anseios e problemas bastante semelhantes aos de boa parte dos sujeitos de sua idade. Seu caráter e personalidade, construídos e reconstruídos ao longo da obra, trazem à tona a questão de que os leitores não estão sozinhos em meio a turbulências que, certamente, enfrentarão.

A metalinguagem, imagens de leitura, diálogo com a história do cinema, igualmente, acrescem a qualidade da narrativa verbo-visual. O leitor é convidado a imergir na história, e, com isso, é convidado também a um passeio histórico e literário.

\section{Referências}

ABRAMOVICH, Fani. Literatura infantil: gostosuras e bobices. 5. ed. São Paulo: Scipione, 1995.

AZEVEDO, Ricardo. Texto e imagem: diálogos e linguagens dentro do texto. In: SERRA, Elisabeth D'Angelo. 30 anos de Literatura para crianças e jovens - algumas leituras. Campinas: Mercado das Letras; Associação de leitura do Brasil, 1998, p. 105-112.

BRASIL. Ministério da Educação. Fundo Nacional de Desenvolvimento da Educação. Edital de Convocação para Inscrição de Obras de Literatura no Processo de Avaliação e seleção para o Programa Nacional Biblioteca da Escola - PNBE 2005. Disponível em: $<$ http://www.fnde.gov.br/index.php/downloads/bibliotecaescola/346editalpnbe2005/download>. Brasília, 2004. Acesso em: 05 out. 2011.

CADEMARTORI, Lígia. Para não aborrecer Alice: a ilustração no livro infantil. In: PAIVA, Aparecida; SOARES, Magda (Orgs.). Literatura infantil: políticas e concepções. Belo Horizonte: Autêntica, 2008. p. 79-90. 
CAMARGO, Luis. Para que serve um livro com ilustrações. In: JACOBY, Sissa (Org.). $A$ criança e a produção cultural - do brinquedo à literatura. Porto Alegre: Mercado Aberto, 2003. p. 271-301.

CRUVINEL, Larissa Warzocha Fernandes. Narrativas juvenis brasileiras: em busca da especificidade do gênero. 2009. 188 f. Tese (Doutorado em Letras e Linguística). Universidade Federal de Goiás, Goiânia, 2009.

FERNANDES, Célia Regina Delácio. Leitura, literatura infanto-juvenil e educação. Londrina: Eduel, 2007.

FERNANDES, Célia Regina Delácio; CORDEIRO, Maisa Barbosa da Silva. Perspectivas para a formação do leitor: a leitura em 25 anos do Menino Maluquinho. Signo, Santa Cruz do Sul, v. 36, n. 60, p. 17-34, jan.-jun., 2011.

GREGORIN FILHO, José Nicolau. Literatura juvenil: adolescência, cultura e formação de leitores. São Paulo: Melhoramento, 2011.

GROPPO, Luís Antonio. Juventude - Ensaios sobre sociologia e história das juventudes modernas. Rio de Janeiro: Difel, 2000.

MAGNANI, Maria do Rosário Mortatti. Leitura, literatura e escola. 2. ed. São Paulo: Martins Fontes, 2001.

PADRINO, Jaime García. Vuelve La polémica: ¿existe la literatura ... juvenil? In: RETTENMAIER, Miguel; Rösing Tania. (Orgs.) Questões de literatura para jovens. Passo Fundo: Universidade de Passo Fundo, 2005, p. 57-72.

SANTOS, Caroline Reis Vieira. A tradução da fala do personagem Hagrid para o português brasileiro e português europeu no livro Harry Potter e a Pedra Filosofal: um estudo baseado em corpus. 2010. 134 f. Dissertação (Mestrado em Estudos da Tradução). Universidade Federal de Santa Catarina, Florianópolis, 2010.

SELZNICK, Brian. A invenção de Hugo Cabret. Texto e ilust. Brian Selznick; trad. Marcos Bagno. São Paulo: Edições SM, 2007.

SIPE, Lawrence. Aprendendo pelas ilustrações nos livros-ilustrados. Tradução de Renata Nakano. Leitura em revista. Rio de Janeiro, n. 1, p. 84-98, out. 2010.

SOUZA, Elaine Leonarczyk. A(s) violência(s) na literatura infantojuvenil brasileira: uma análise a partir do PNBE 2013. 2016. 174 f. Dissertação (Mestrado em Letras). Programa de Pós-Graduação em Letras, Universidade Estadual de Maringá, Maringá, 2016.

VERDOLINI, Thais Helena Affonso. Tradução de literatura infantojuvenil contemporânea no Brasil. In: CONGRESSO INTERNACIONAL DE LEITURA E LITERATURA INFANTIL E JUVENIL. 2012, Porto Alegre. Anais... Porto Alegre: PUCRS, 2012. p. 1-15. Disponível em: < http://ebooks.pucrs.br/edipucrs/anais/IIICILLIJ/Index.html >. Acesso em: 15 jan. 2013.

WERNECK, Regina Yolanda. O problema da Ilustração no livro infantil. In: KHÉDE, Sonia Salomão (org.). Literatura infanto-juvenil: um gênero polêmico. 2. ed. Porto Alegre: Mercado Aberto, 1986. p. 147-154. 


\section{Créditos das imagens}

Figura 1, A invenção de Hugo Cabret (2007, s/p).

Figura 2, A invenção de Hugo Cabret (2007, s/p).

Figura 3, A invenção de Hugo Cabret (2007, s/p).

Figura 4, A invenção de Hugo Cabret (2007, s/p).

Figura 5, A invenção de Hugo Cabret (2007, s/p).

Figura 6, A invenção de Hugo Cabret (2007, s/p).

[Recebido em $1^{\circ}$ de fevreiro de 2016 e aceito para publicação em 29 de abril de 2016]

The invention of Hugo Cabret: ilustration e cinema in the youth literature

Abstract: This paper analyzes the book The invention of Hugo Cabret, by Brian Selznick (2007), set in Paris during the 1930s. The focus of this study is verify the dialogue verbal and visual in the narrative, integral of the 2013 colletcion of the National Program of School Library - PNBE. The book brings the ficcional history of the Hugo Cabret, livro traz a ficção da história de Hugo Cabret, who lost his father and que perdeu o pai e needs to survive alone, and too the true story of turn-of-the-century French pioneer filmmaker Georges Méliès. The narrative noteworthy is thus three questions: verbal and visual dialogue; the representation of the cinema; the representation of the story of George Méliès. In this perspective, the analysis is based mainly in Camargo (2003) and Groppo (2000).

Keywords: youth literature. Verbal and visual. PNBE.

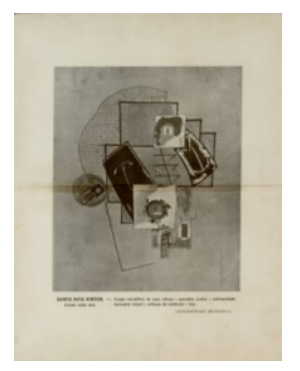

